\title{
SPEAK: MOVIMENTO AUTÊNTICO, 'TEXTO ENCARNADO’ E PERFORMANCE COMO PESQUISA ${ }^{1}$
}

\author{
Emma Meehan \\ PhD. \\ Pesquisadora no Centro de Pesquisa em Dança (CDaRE) da Universidade de Coventry (Reino Unido) \\ E-mail: ab4488@coventry.ac.uk \\ Tradução: Cláudia Müller Sachs \\ Doutora em Teatro pela UDESC. Professora na Universidade Federal do Rio Grande do Sul \\ E-mail: claudiasachs@terra.com
}

Resumo

Neste artigo, vou examinar a relação entre movimento e linguagem na minha prática de Movimento Autêntico, enfocando o escrever para e sobre a performance. Embora práticas somáticas como o Movimento Autêntico promovam a integração corpo-mente e muitas vezes usem a reflexão baseada na linguagem sobre a experiência, frequentemente encontro perspectivas conflitantes na relação entre corpo e linguagem nos contextos nos quais eu trabalho. A fim de investigar ideias de divisão e integração entre movimento e linguagem, abordo uma performance como projeto de pesquisa chamada Speak (Falar). Trabalhei com o "texto encarnado" de Janet Adler como estratégia para a exploração. A partir desse procedimento, que é um aprofundamento do processo de estudo e prática com palavras em Movimento Autêntico, propus a pergunta: Qual é a relação entre movimento físico e linguagem na prática de Movimento Autêntico? Com a ênfase na integração corpo-mente e na articulação da experiência em Movimento Autêntico, a abordagem poderia oferecer métodos para o crescente número de praticantes-pesquisadores que entram na academia interessados em questões de reflexão sobre a prática do corpo através da escrita.

\section{Palavras-chave}

Movimento Autêntico. Escrita. Fala. Linguagem. Performance. Prática como pesquisa
Abstract

In this article, I will examine the relationship between movement and language in my Authentic Movement practice, focussing on writing for and about performance. Although somatic practices such as Authentic Movement promote body-mind integration and often use language-based reflection on experience, I have often encountered conflicting perspectives on the relationship between body and language across the contexts that I work in. In order to investigate ideas of division and integration between movement and language, I undertook a performance as research project called Speak. Working with Janet Adler's 'embodied text' as a strategy for exploration, which is a deepening of the process of study and practice with words in Authentic Movement, I addressed the question: What is the relationship between physical movement and language in Authentic Movement practice? With the emphasis on body-mind integration and articulation of experience in Authentic Movement, the approach could offer methods to the increasing number of practitioner-researchers entering the academy and grappling with issues of reflecting on embodied practice through writing.

Keywords

Authentic Movement. Writing. Speaking. Language. Performance. Practice as Research

1 Artigo originalmente publicado em MEEHAN, Emma. Speak: Authentic Movement, 'Embodied Text' and performance as research. Journal of Dance \& Somatic Practices, v. 7, n. 2, p. 313-329, 2015. 
Introdução:

discursos conflitantes sobre movimento e linguagem

Tenho frequentemente encontrado discursos dissonantes sobre a relação entre linguagem e corpo nos diferentes ambientes em que trabalho - universidade, contextos de treinamentos de performance e de educação somática. Na minha experiência, a relação entre movimento e linguagem às vezes pode ser vista como um desafio, com a linguagem sendo considerada como aquilo que interrompe ou apaga a experiência corporal. Ou a linguagem pode ser vista como produtiva e geradora enquanto um aspecto da experiência do corpo-mente. Minha formação somática em Movimento Autêntico e Body-Mind Centering ${ }^{\circledR}$ com Joan Davis na Irlanda explorava a inter-relação entre movimento e linguagem de muitas maneiras - incluindo expressões vocais como parte da expressão pelo movimento, reflexão falada e escrita seguindo o movimento, texto ou sons informando a prática do movimento, facilitação por meio da linguagem e do toque e assim por diante. Portanto, minha opinião é que o Movimento Autêntico visa integrar movimento e linguagem, onde ambos fazem parte dos processos de percepção e de ação. A capacidade reflexiva para articular a experiência também é um ponto de foco da prática, usando corpo-mente e corpo-linguagem juntos. No entanto, trabalhando com profissionais da performance tanto dentro como fora dos contextos de movimentos somáticos, às vezes ouvia argumentos contra o falar sobre movimento e uma desconfiança de que a linguagem possa apagar a experiência. Desta forma, a linguagem pode ser vista como aplicada ao trabalho, em vez de uma articulação e extensão do processo em si.
A resistência à linguagem poderia ser vista como parte de uma reação contra o dualismo cartesiano, onde Descartes foi interpretado como o que valorizava a atividade mental-e-baseada-no-pensamento em detrimento da experiência corporal. Andrée Grau (2011, p.7) aponta que Descartes de fato não propunha uma separação completa da mente e do corpo, e questiona "o pressuposto da superioridade da [mente sobre o corpo] que é geralmente atribuído a Descartes e depois apresentado como uma 'típica' compreensão ocidental do corpo". Ao mesmo tempo, o conhecido desprezo cartesiano pela resposta encarnada em relação à investigação intelectual pode ser considerado algo que sugere uma desconfiança recíproca em relação ao "pensar". No âmbito de um quadro dualista, então, o pensar poderia ser assumido como algo que desconecta o corpo da experiência, e a linguagem como aquilo que provém de uma racionalização que segue a experiência, o que pode afastar do valor intrínseco dos fenômenos corporais. $\mathrm{O}$ desejo de promover a experiência fora do enquadramento linguístico poderia ser considerado como um passo necessário para restabelecer a importância da percepção corporal e dar-lhe um lugar nos discursos de conhecimento. No entanto, tal posição poderia reforçar a divisão corpo-mente que o trabalho somático desafia.

A desconfiança da linguagem como articuladora da experiência também poderia emergir das "crenças de que há algo imutável e eternamente autêntico acerca do corpo e do movimento de uma forma que é menos verdadeira para a linguagem e para a palavra falada" (Murray e Keefe 2007, p. 21). O título 'Movimento Autêntico' aparece para manter o pressuposto de um self estável, autêntico, que pode ser derivado do movimento. Entretanto, 
na prática de Movimento Autêntico, os movimentos aparecem e desaparecem com base em elementos contextuais e as identidades nunca são, portanto, estáveis, mas emergem de relações pessoais e ambientais evolutivas. Além disso, pode surgir material inconsciente no corpo em Movimento Autêntico por um processo de diferença e substituição, como um impulso inconsciente pode tomar uma série de diferentes formas durante uma sessão, tais como voz, gesto, arquétipos e assim por diante. De fato, Derrida sugere que a teoria psicanalítica de Freud do inconsciente refere-se a um processo de diferenciação, mais do que à existência de uma verdade estável e imutável através do corpo. Derrida comenta que:

[...] o inconsciente difere, como sabemos, uma auto-presença a si escondida, virtual ou potencial. $O$ inconsciente difere-se, o que significa sem dúvida que ele se tece de diferenças e também que envia, que delega representantes, mandatários; mas não há nenhuma hipótese de que o delegante "exista"1. (1982, p. 20-21)

O impulso pode ser reprimido pelo indivíduo, influenciado por restrições pessoais, sociais e culturais, e tornar-se parte do material inconsciente que aparece no corpo. No entanto, esses "aparecimentos" marcam desaparecimentos, por serem vestígios de material inconsciente - que podem igualmente ser aplicados ao movimento como linguagem, como no "ato falho" proverbial de Freud.

A prática como pesquisa (também conhecida como pesquisa artística, performance como pesquisa, pesquisa guiada pela prática, prática orientada pela pesquisa e assim por

1 N.do T.: Optamos por utilizar a tradução utilizada na publicação brasileira. DERRIDA, Jacques. Margens da Filosofia. Campinas, SP: Papirus, 1991, p.53. diante) celebra amplamente o engajamento ativo através do corpo do pesquisador como uma modo de conhecimento, e vem desenvolvendo um perfil internacional como uma metodologia de pesquisa validada, ainda que em diferentes graus em diferentes culturas (Nelson 2013, p. 11-17). Tais discursos tentam evitar a tendência dualista de ver o corpo e a mente como separados e, portanto, colocá-los numa hierarquia de um sobre o outro. Em vez disso, há um processo de exploração da maneira como eles trabalham juntos para informar conhecimento e descobrir ideias que não estariam disponíveis sem processos de experiência corporal, reflexão cuidadosa, atividades físicas, colaboração com os outros, documentação e articulação através de várias mídias. Em um processo de estratificação, gamas de experiência e de expressão podem ser reveladas - que incluem uma linguagem de corpomente-movimento como elementos inter-relacionados do processo.

De fato, o desenvolvimento generalizado da prática como pesquisa nas artes cênicas criou uma proliferação (e uma urgência na abordagem) de formas de escrita em torno, através, em paralelo e sobre a prática da performance. Henrietta Bannerman observa que: "Podemos reconhecer, a partir do crescente número de livros, artigos e documentos escritos por coreógrafos, que há uma crescente tendência de subsídios que representam o pensamento sobre atividades corporais" (2010, p. 474). A autora relaciona essa tendência ao "aumento do número de coreógrafos, tanto emergentes quanto experientes, que entram na academia e, como resultado, são chamados a escrever sobre seus trabalhos" (2010, p. 480). Emergindo de um pano de fundo desse tipo de debates sobre práticas corporais e articulações 
baseadas em linguagem, minha prática como projeto de pesquisa chamado Speak examina a relação entre movimento e linguagem na prática de Movimento Autêntico. Nesse processo, busco encontrar formas de linguagem que possam falar, responder, enunciar e refletir sobre a experiência. Através do processo, identifiquei abordagens para reflexão como uma experiência de corpo-mente que pode ser explorada num processo de formas vocais e escritas, e 'texto encarnado' como uma metodologia emprestada da prática de Movimento Autêntico. Primeiramente, vou apresentar como a prática de Movimento Autêntico trabalha com linguagem, antes de passar para a descrição de minha performance como projeto de pesquisa.

\section{Linguagem na} prática de Movimento Autêntico

O Movimento Autêntico foi desenvolvido por Mary Starks Whitehouse a partir do processo de "imaginação ativa" da psicanálise junguiana, na qual o paciente traz impulsos inconscientes para uma forma criativa. Isto é praticado através do movimento, quando o movente ${ }^{2}$ fecha seus olhos, espera por um impulso que toma forma física e segue sua expressão. Mais tarde, Janet Adler desenvolveu especificamente o papel da "testemunha". A testemunha pode ser o terapeuta ou outro membro do grupo que vigia o movente, enquanto reflete sobre sua própria experiência desse movimento. O movente é então treinado para desenvolver uma "testemunha interna", que é um meio de testemunhar o seu próprio movimento em relação ao ambiente (incluindo outros moventes). Depois de se moverem

2 N.do T. Sobre a escolha do termo "movente": no original "mover", aquele que se move. por um determinado período de tempo, o movente e a testemunha "processam" o material do movimento através da escrita, de obras de arte, e da palavra falada.

Num cenário terapêutico, o Movimento Autêntico enfatiza a autoridade do paciente, com o terapeuta num papel de facilitador que explora a saúde física e psicológica. Na verdade, a experiência subjetiva do paciente (e muitas vezes a reflexão subjetiva ou o testemunho do terapeuta) é vista como necessária para a obtenção de insights ${ }^{3}$ sobre questões psico-físicas. No processo, movimento e linguagem não são colocados numa ordem hierárquica, com um sendo considerado mais valioso do que outro. A linguagem pode ser incluída na sessão de movimento e a experiência muitas vezes é processada através do testemunho escrito e verbal que emerge da experiência de corpo-mente. Esse processo é claramente estruturado, particularmente em torno do uso da linguagem, como parte da segurança do trabalho - o que sugere que os riscos do uso de linguagem são tão relevantes quanto aqueles em torno de ação corporal e de toque em algumas formas de psicanálise. Phelan comenta sobre Freud que: "a psicanálise clássica abandonou a cura física em favor da técnica clínica da cura pela fala. Uma técnica que dependesse demais do toque significava um risco enorme de uma revolução epistemológica que o líder visionário estava determinado que fosse, acima de tudo, científica" (1996, p. 90). O Movimento Autêntico funciona contrariamente a isto, combinando movimento, linguagem e às vezes toque (por exemplo, entre os moventes), e convidando experiências subjetivas a infor-

3 N.do T. Optamos por manter o termo original "insight" que abarca a ideia de descoberta, tomada de consciência, discernimento, percepção. 
marem a reflexão.

O papel da linguagem no testemunho foi desenvolvido por Janet Adler a partir de seu treinamento com o psicólogo John Weir. Tina Stromsted e Neala Haze (2007, p. 59) observam:

Ao aprenderem a conter suas próprias experiências e tendências, os moventes e as testemunhas empregam certos protocolos, incluindo um quadro linguístico, para ajudá-los na desafiadora tarefa de diferenciar percepção clara de projeção. "Linguagem Percebida", como desenvolvida por John Weir (1975), é uma prática de fala que Adler integrou ao Movimento Autêntico como parte desse protocolo ... Seu objetivo é a criação de uma linguagem que não é nem crítica nem interpretativa. Testemunhas fazem declarações do "eu" que localizam as percepções (e os sentimentos que as acompanham) naquele que fala, e não em objetos externos (os moventes).

$\mathrm{Na}$ "linguagem percebida" de Weir, a testemunha usa a primeira pessoa no tempo presente ao oferecer testemunho. Isto serve para confirmar que qualquer testemunho é uma experiência subjetiva, mais do objetiva, daquilo que ocorreu. Testemunhar no tempo presente permite que a testemunha retorne à memória física e emocional do movimento para re-experimentá-la.

Como mencionado anteriormente, minha compreensão da relação entre movimento e palavras foi orientado pelo meu treinamento de Movimento Autêntico com Joan Davis. Seu programa de treinamento e prática da performance integra linguagem, com o termo "movimento" sendo entendido como algo que inclui palavras, imagens, sensações e histórias que se movem através do soma; enquanto as práticas de testemunhos incluem desenho, escrita e fala, que tentam incidir o corpo e a mente num processo reflexivo. Davis observa em sua prática de testemunho que:

Estou à procura de palavras incorporadas - palavras que possam oferecer ao ouvinte um sentido físico e 'sentido' do que aquelas palavras estão transmitindo. É a combinação tanto da escolha da palavra quanto do orador falando-a a partir de um sentido corporal percebido que faz uma fala encarnada. $(2007$, p. 187$)$

Em seu livro sobre a prática de Movimento Autêntico chamado Offering from the Conscious Body, Janet Adler (2002) sugere que quando os moventes vão se tornando mais experientes, eles podem fazer "ofertas" ou partilhas de Movimento Autêntico através de formas, tais como a escrita e a dança. Sua abordagem sobre o oferecer a partir da linguagem é descrita como 'texto encarnado', e ela sugere que, quando o movente pratica a linguagem do testemunho, ele ou ela pode afrouxar a estrutura em torno do processo. Ela observa que:

\begin{abstract}
Quando as pessoas exploram escrever a experiência incorporada ao invés de escrever sobre ela, elas podem descobrir novas formas de conhecer a distância entre a experiência e a palavra, bem como a ausência de tal distância. O processo de escrita traz uma maior consciência de palavras que emanam diretamente do corpo. (2002: 154)
\end{abstract}

Seguindo a ideia de Adler de "escrever a experiência" em vez de sobre ela, venho também experimentando o escrever sobre o sentido geral de uma sessão de movimento, em vez das especificidades de um movimento. Em vez de documentar as manifestações físicas da experiência, escrevo a minha resposta com uma mente aberta ao sentido geral do que emergiu. A primeira vez que escrevi dessa 
forma foi uma surpresa perceber que esta camada de experiência existia, e só foi trazida à consciência através do processo de escrita.

A escrita se engaja ao movimento, retornando ao corpo, expressando experiências, mas também desvendando, separando e criando novas formas, fazendo algo novo aparecer ou se tornar mais claro. A escrita pode alterar a experiência, mas é também um meio para experimentar. Ao liberar a forma da resposta escrita, reconhece-se que há uma perda inerente à escrita, alterando a substância material que está sendo articulada. A inscrição tem uma vida própria e, em vez de representar ou preservar o movimento, existe a possibilidade de desfrutar as oportunidades geradoras, insights e expressões que aparecem através da escrita. A frase evocativa 'arquivo cinestésico', de Alys Longely (2010), sugere um processo de coleta de registros de movimento ao mesmo tempo que documenta percepções somáticas, cruzando as "porcas e parafusos" físicos da ação com qualidades subjetivas.

\section{Performance como pesquisa: Speak e investigando 'texto encarnado'}

Speak é uma performance que se desenvolveu a partir de uma prática contínua de permitir que a linguagem informe o movimento, e que o movimento informe a linguagem, apoiado pela prática de Movimento Autêntico 4 . Adler (2002, p. 176) observa em sua prática de texto incorporado que:

\footnotetext{
4 Gostaria de revelar o apoio da Dance Irland Residency, Sligo Arts Office Bursary e do Programa Espacial de Incubação do Conselho Municipal de Dublin. Também recebi orientação da diretora de movimento Sue Mythen e da marionetista/artista visual Niamh Lawlor, e trabalhei com a performer Mary Cate Smith como parte do processo. O processo também foi informado pelas práticas de Longely(2010) para trabalhar com movimento e escrita.
}

\begin{abstract}
Quando as palavras retornam ao gesto, voltam para o corpo, as pessoas são incentivadas a explorar um reentrar ou um entrar pela primeira vez de uma nova maneira. Estamos passando de corpo para palavra e de volta ao corpo novamente, mas, dessa vez, por causa do desenvolvimento da testemunha interior, estamos chegando a um novo lugar.
\end{abstract}

Entro em ciclos de movimento seguindo escritas sem intenção de revisitar, mas a escrita começa a se tornar parte da informação que é transportada no meu corpo-mente. Focando minha atenção no meu mover através de uma prática de escrita, começo a perceber hábitos, alterações, padrões familiares e caminhos específicos ou temas. Continuando a prática de rodadas de movimento e escrevendo regularmente, eu também convido a minha atenção a vocalizar e falar como 'bolsos' de experiência em meu mover. Às vezes eu me movimento com meus olhos abertos para fazer conexões entre impulso interno, externalização no espaço através do movimento, som e fala, e o ambiente ao meu redor.

Minhas anotações no diário para desenvolver Speak registram sensações, sentimentos, pensamentos e movimentos que ocorreram, e acompanham uma história do meu medo de ficar parada, empurrando o corpo, seguido de exaustão e de uma sensação de flutuar sem qualquer força ou energia. Há também uma nova fisicalidade emergente que inclui raiva, empurrando, batendo e saltando seguida por movimentos que são ao mesmo tempo vibrantes e descontraídos, não de empurrar, mas não colapsados. Querendo compartilhar um pouco do processo por meio da performance, revisitei meu diário para observar as diferentes correntes do conteúdo - descrições de movimento, palavras que aparece- 
ram, padrões repetidos de movimento, e assim por diante. Comecei a editar os escritos para esclarecer o que restava da minha experiência e também comecei a revisitar alguns dos materiais de movimento que haviam se destacado na minha memória. Isso evoluiu para um vocabulário de movimentos e uma sequência escrita de textos poéticos que eram ligados entre si por meio de temas amplamente relacionados a exaustão, esforço do corpo, colapso e hiperatividade. Criei roteiros com desenhos de sequências de movimentos e palavras escritas em cartões que eu dispunha em ordens diferentes, experimentando diferentes sequências de movimento e falando ao mesmo tempo. Rearranjei os cartões e testei cada nova sequência, até que encontrei um caminho que me reconduziu à experiência da minha prática, a qual aconteceu durante o período de um ano. Um extrato da partitura tem o seguinte teor:

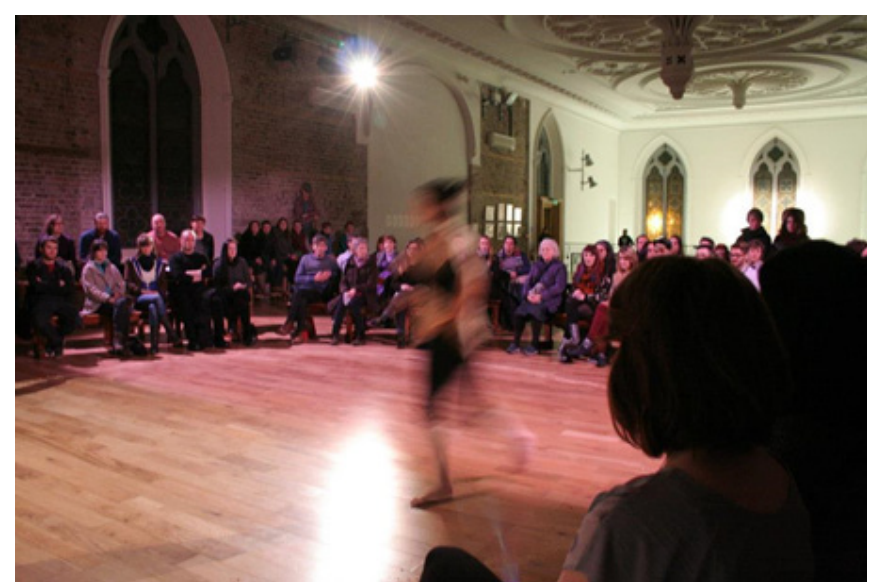

Figura 1: Speak (Fala), na Unit One Performance Art Night, Smock Alley Banquet Hall, Dublin. Crédito: Ciara McKeon.

(Ela começa a correr, correndo em círculos. A corrida começa relaxada e fácil, alongando as costelas superiores com quadris e cintura soltos.)

\section{Pé no chão}

Som de ecos

\section{Criando tempo onde não há nada sólido}

(A corrida começa a aumentar a velocidade)

A contagem de tempo

A ordem na minha vida

O medo de chegar a lugar nenhum

De me perder

(Ela prende seus pés firmemente no chão e pára)

Eu paro e ouço minha respiração pesada

E o coração batendo

Eu paro

$\cdots$

(Ela se abaixa sobre os quadris para dar uma boa olhada em volta. Ela se move com mãos e pés em uma posição de cão virado para baixo, vira a cabeça para dentro na direção do peito e chuta os pés para trás, em seguida, levanta a cabeça e a parte superior da coluna para olhar ao redor outra vez. Isto é repetido várias vezes. Em seguida, ela inclina seu peso fortemente sobre suas mãos. Seu peso cede em direção ao solo e ela se enrola no chão.)

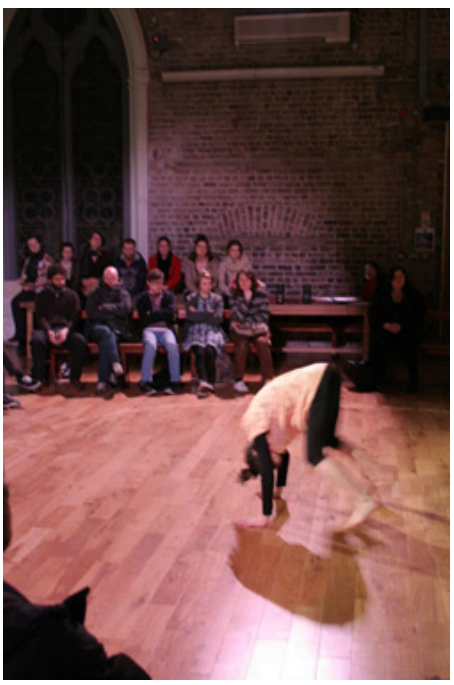

Figura 2: Speak, em Unit One Performance Art Night, Smock Alley Banquet Hall, Dublin. Crédito: Ciara McKeon 
Há um momento

Quando eu paro

E me pergunto

Se há qualquer necessidade de se mover O tempo passa

Anos perdidos

Perda do coração

Um corpo de 30 anos oscila

E então apaga

Incerto. (Extrato de Speak, 2013)

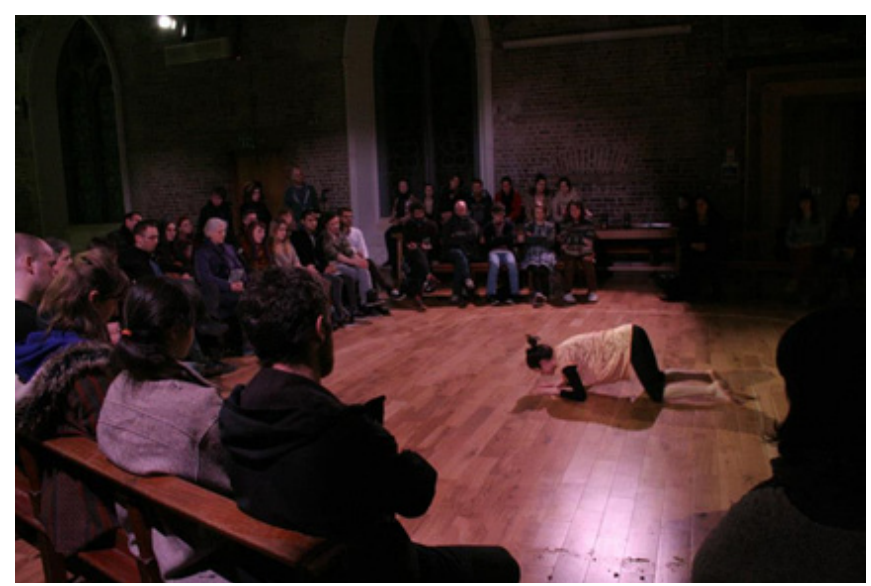

Figura 3: Speak, em Unit One Performance Art Night, Smock Alley Banquet Hall, Dublin. Crédito: Ciara McKeon

Eu dei o título Speak para a peça, pois meu corpo-mente estava falando através da prática contínua de movimento e escrita - eu estava agora ouvindo distintamente o que ele estava articulando, o que eu poderia não ter notado sem ter realizado essa prática.

Para mim, a prática de Movimento Autêntico oferece uma intervenção em uma sociedade que valoriza a eficiência, o progresso, a produtividade e a ação. Por outro lado, às vezes a prática levou-me a um tal estado de repouso que muitas vezes eu me perguntava se algum dia eu iria sentir a necessidade de me mover novamente. Durante a realização de Speak, às vezes encontrei um lugar entre esses limites. No entanto, eu também caía em padrões familiares e brincava com o contínuo processo de re-localizar este "entre". O mover e o escrever juntos foi o que me ajudou a desenvolver insights no processo, criar material para a performance e, finalmente, para escrever sobre a prática dentro do quadro de 'pesquisa'.

Apresentei Speak pela primeira vez na Unit 1 Performance Art Night na Smock Alley, em Dublin, em fevereiro de 2013. Na performance, passei pelos movimentos da peça sem vivê-los plenamente, e me senti desligada do ambiente e do público. Além do fato de que eu estava me mudando da Irlanda para o Reino Unido, na época, o que me deu alguma sensação de desconexão, eu também me perguntava se a qualidade "ensaiada" de reprodução do material físico e vocal de Movimento Autêntico em outro contexto significava que ficaria "fora do lugar". Como um outro experimento, também realizei Speak na conferência Dance and Somatic Practices na Universidade de Coventry, Reino Unido, em julho de 2013. Em Coventry decidi adicionar um ponto de partida diferente para a performance, que adicionava uma ação que podia mudar quando ocorresse durante a performance. A peça agora começava com a montagem de um estande de bolos, dispondo brownies que eu assara à exposição e comendo um deles. Enquanto eu comia os brownies, minhas mãos tremiam com o nervoso da performance e minha garganta ficou seca. Tomei um gole d'água, mas minha mão tremia tanto que a água derramou, o que provocou risos em mim e no público. Uma pessoa do público, Hilary Kneale, observou que:

Não consigo me lembrar de suas palavras, mas vi que sua mão estava tremendo enquanto segurava o copo d'água. A água no copo, a água tremendo, um espelho visceral do seu estado. Naquele momento exato da 
performance seu corpo estava comunicando sua condição. Ela cortou o bolo em pedaços menores, comeu o bolo, estaria ela tentando criar alguma ordem no cortar e comer? Quando ela falou diretamente para mim e também para eles, senti uma crescente sensação de caos imanente, uma inflexão dentro da qual ela se movia. (Kneale, comunicação pessoal)

As ações de comer o bolo e beber a água haviam convidado a um momento para experimentar minha resposta multisensorial em relação ao público e ao ambiente, assim como para acolher minha experiência desestabilizada daquele momento. No entanto, Kneale observa que ela não consegue lembrar as palavras tanto quanto as ações, indicando, talvez, que o texto que eu recolhera a partir do Movimento Autêntico não era tão relevante para ela naquele momento. Enquanto pode-se sugerir que o texto já fazia parte da minha história corporal e, portanto, de alguma forma estava informando o meu movimento, eu não tinha conseguido fazer a transição para um modo de falar em relação ao contexto ao meu redor. Outro membro da plateia, Adam Benjamin, comentou que:

A peça teve um início muito envolvente que parecia incluir o público e estabelecer um sentido de você ser "exatamente como" nós fazendo algo no espaço do qual fazíamos parte também. Para mim isso escapou gradualmente, ao você se tornar mais focada na atividade, que começamos a 'assistir' e de alguma forma o imediatismo da sua conexão conosco (e, portanto, a conexão com a peça) começou a se desviar. Eu me senti muito mais longe de você do que eu tinha sentido no início, o potencial de humor e partilha havia desaparecido quando da conclusão. Eu meio que queria você de volta com a gente. (Benjamin, comunicação pessoal)
Conforme descrito por Benjamin, eu perdi minha atenção consciente em relação ao público e ao entorno ao longo do trabalho. Fiquei presa à partitura e ao texto, o que não permitiu a abertura suficiente para envolver o lado 'prático' do Movimento Autêntico de ser um processo contínuo de mudança. Também é interessante que minha "ação" no início da peça era em silêncio, e eu não tinha encontrado uma maneira de incluir a linguagem como parte do desdobramento da atenção para o meu corpo no contexto. Em meu diário, anotei:

Correndo rápido, quero sentir de novo
como fiz antes. Tento alcançar o mes-
mo sentimento, mas ele está fora do
meu alcance, não importa o quão rápi-
do eu corra. Meu corpo não é o mes-
mo, no caos e na superação, eu não
posso conter todas as informações
que estou recebendo e me sinto de-
sarticulada de minhas palavras. Vou
com os movimentos. Meu corpo está
tentando significar, mas o quê? O im-
pulso, a unidade, isso se perdeu ago-
ra? (Diário da Autora, 2015)

\section{Reflexões sobre Speak, processo e contexto}

Meus experimentos em movimento, fala e escrita consideram o potencial decorrente do engajamento corpo-mente em conjunto no processo de 'texto encarnado' de Adler e o desenvolvimento dessas ideias através da performance. Sugiro que a discussão sobre a exploração da linguagem de Kristeva (1984), que emerge entre o corpo social e somático, pode ser válida no entendimento do texto encarnado. Kristeva argumenta que:

o tipo de atividade incentivada e privilegiada pela sociedade (capitalista) reprime o processo que permeia o corpo e o sujeito, e que deve, portanto, romper com a nossa experiência inter- 
pessoal e intersocial se quisermos ter acesso ao que é reprimido no mecanismo social: a geração de significado (1984, p. 14).

Ao quebrar hábitos de significação, como nossas práticas de se mover, falar e escrever, estamos revelando os mundos sociais em que vivemos sob novas perspectivas e derrubando os tipos de discurso que estão sendo criados. Interrompendo os limites dentro dos quais nos movemos-falamos-escrevemos, um excesso de entendimentos, por vezes ininteligíveis, fragmentários, confusos e perspicazes do mundo em que vivemos, pode potencialmente vir à tona.

Embora este seja um processo difícil, e conheci o meu próprio 'fracasso' de me engajar plenamente nele, é uma prática voltada para uma compreensão mais profunda dos modos de significação na esfera do público que pode ser informado pelo corpo-mente inteiro, a produção de um sujeito linguagem-movimento que vive ali dentro, através e além da estrutura sócio-política e cultural. Kristeva explica como os materiais criativos, sensuais, somáticos e impulsivos podem ser acessados através da linguagem poética e, portanto, ela sugere que a escrita experimental pode "sublinhar os limites do discurso socialmente útil e atestar o que ele reprime: o processo que excede o sujeito e suas estruturas comunicativas" (1984, p. 16). Em Speak, os materiais de movimento e de linguagem desenvolvidos no processo de realização moveram-se entre padrões familiares e novos materiais que me surpreenderam e 'ultrapassaram' comportamentos repetitivos.

Kristeva (1984) discute como impulsos, tendências ou cargas de energia pulsam através do corpo do sujeito, através da ordem regulada do corpo social ao mesmo tempo que o rompe. Sua teoria da semiótica "está associada aos ritmos somáticos íntimos do corpo e da linguagem quando ela é experienciada antes do discurso" (Groz 2005, p. 174). Aqui é sugerido que a linguagem pode ser, portanto, tanto um ímpeto impulsivo quanto uma forma culturalmente informada quando ela emerge. Experiências fluidas de movimento e linguagem estão, portanto, subjacentes à articulação, e como parte do processo de tomarem forma para a compreensão, podem desvendar interrupções à nossa percepção. A linguagem pode também explorar as qualidades sentidas de movimentos, o que possibilita revelar os discursos contidos dentro deles. Desta forma, os construtos sociais e culturais, bem como os aspectos "semióticos" da experiência humana podem ser descobertos através das práticas de movimento e de linguagem. Em Speak, o trabalho com texto encarnado me permitiu explorar as tendências emergentes do corpo e da linguagem através de formas de movimento, fala e escrita, que revelaram discursos sobre as pressões da produtividade e o desejo de abordagens mais sustentáveis para viver.

Em Speak, movimento e linguagem conectaram-me a mim mesma e ao meu entorno durante o processo, mas isso não aconteceu na maior parte da performance. Bainbridge Cohen (1993, p. 6) sugere que:

Nossa capacidade de incorporar processos estruturais e fisiológicos de respiração subjacente e de produção vocal nos oferece uma outra importante maneira para estabelecer nossa relação conosco mesmos e com o nosso meio ambiente.

Aqui, ela descreve como a consciência corporal pode dar suporte ao falar, como um processo de comunicação e intercâmbio 
com o meio ambiente ao nosso redor. Embora a repetição de movimento em Speak também parecesse desconectada, a transição do material escrito "passado" para forma falada ao vivo foi particularmente difícil para mim, pois eu não conseguia me reengajar com este material passado na minha posição atual. A performance foi uma peça "acabada" retirada da prática de Movimento Autêntico, enquanto que o processo inicial havia se engajado com os fenômenos decorrentes na época. A prática de Movimento Autêntico na performance levanta questões sobre como continuar a se envolver com valores centrais de responsividade e adaptação na prática, para se conectar com o novo ambiente encontrado e para provocar uma capacidade de mudança. Malaika Sarco-Thomas (2014, p.194) observa que no trabalho somático mais genericamente "a valorização da escolha consciente sobre o hábito cego envolve perceber e questionar parâmetros sobre os próprios padrões e a capacidade de mudar". Como, então, o trabalho de performance com o Movimento Autêntico e a linguagem pode incentivar um compromisso com o contato, a troca, a interação e a colaboração dentro de cada novo contexto de ensaios e de performance?

O papel do público foi abordado por Kneale quando ela comentou sobre a performance que:

Eu estava consciente, no momento, de fortes respostas corporais ao jeito que ela falou-nos como 'espectadora' tanto através de suas palavras como pelo seu corpo. Eu não poderia "responder" ao seu diálogo quase confessional enquanto eu continuava mantendo o meu papel na peça como 'espectadora'. (Kneale, comunicação pessoal)

Aqui ela observa que se sentia apri- sionada dentro de um papel separado como 'espectadora', sem oportunidades para responder. Na prática de Movimento Autêntico, as ações subjetivas vocais, escritas ou de movimento, e seus reflexos correspondentes, surgem através de uma associação com a paisagem pessoal, com a percepção do entorno e da relação com as testemunhas. Em Speak, eu não tinha pensado em como eu poderia trazer esses relacionamentos para a performance, considerando o papel do público e do contexto na interação. Eu não tinha claro como eu poderia desenvolver um sentido de conversa ou diálogo, que faz parte da prática, com o local e o público como partes da paisagem da performance - e a peça tornou-se menos porosa ao tornar-se performance.

Por um lado, eu tinha o desejo de trabalhar com a linguagem produzida a partir do processo e, por outro, de encontrar maneiras de compartilhar isso que mantinha o desdobramento inerente à prática de Movimento Autêntico - de consciência corpo-mente, escuta, desconhecimento e intercâmbio com o contexto. Assim, comecei a pensar para além da ideia de 'texto encarnado' nas propostas de Adler, que sugerem que as práticas de 'diálogo' ou 'conversa' podem ser boas metáforas, bem como as modalidades para considerar Movimento Autêntico e linguagem na performance no futuro. Recentemente, Jane Bacon e Vida Midgelow criaram um trabalho de performance chamado Skript que "engaja noções encarnadas, sentidas, modalidades de improvisação e de colaboração em relação ao ato de escrever" (2014a, p.73). Skript envolve um processo interativo com o público de construção de uma linguagem lúdica e dialógica em relação ao corpo e dança. Bacon e Midgelow (2014a) também descrevem a preparação para 
a performance através de uma abertura para o corpo e o público para facilitar o processo de construção de linguagem. Suas estratégias são pertinentes para o desenvolvimento do processo de integração de Movimento Autêntico, linguagem e performance. Entretanto, em Speak eu também estava à procura de maneiras em que fala e escrita articuladas durante o processo da prática de Movimento Autêntico pudessem tornar-se parte do tecido do performance, como o 'texto encarnado' poético que permanece e os movimentos físico-vocais surpreendentes que surgiram. Poderiam ser desenvolvidos modelos para trabalhar com textos produzidos durante uma prática de Movimento Autêntico. Tais modelos possibilitariam encontrar modos interativos para compartilhar textos pré-escritos, tais como exposições participativas onde sessões de movimentos filmadas são compartilhadas juntamente com escritos de testemunhas e apresentadas em camadas com respostas de visitantes ao longo do tempo; performances para apenas uma pessoa que usam textos pré-escritos como ponto de partida de conversação; ensaios abertos ou performances duracionais que convidam o público a ver os textos pré-escritos no contexto de um processo; ou muitas outras possibilidades ainda a serem descobertas.

Por fim, o Movimento Autêntico me ofereceu maneiras de escrever sobre experiências que vêm da prática do movimento e da performance-baseada-no-corpo entre os contextos que habito como praticante e pesquisadora. Wolff (1998, p. 244) comenta que "em vez da sugestão de que dançar é escapar das limitações da racionalidade linguística, encontramos a ideia de que a linguagem em si pode ser tornada inovadora e crítica ao aprendermos a escrever, pensar e falar no modo de dan- ça". Nesse sentido, meus experimentos com movimento e escrita consideram o potencial decorrente do engajamento do corpo-mente para refletir sobre insights oriundos da práticas como pesquisa. Sugiro que a prática de Movimento Autêntico tenha desenvolvido métodos reflexivos originais a partir do testemunhar o texto incorporado que pode ser útil para praticantes-pesquisadores no desenvolvimento da "capacidade de encontrar uma linguagem, de tornar-se articulada, de dentro do trabalho" (Bacon e Midgelow 2014b, p.15) . Minha proposta para conversas e diálogos sobre Movimento Autêntico poderia também oferecer possibilidades de partilha dessa reflexão sobre a prática de maneiras que convidam contato e troca dentro de variados contextos acadêmicos e de performance. "Ofertas" de pesquisas baseadas na prática de materiais físicos, verbais e escritos poderiam ser formuladas como um encontro inacabado onde o potencial para interação é disponibilizado no diálogo entre aquele que apresenta e o público, suscitando provocações, incertezas, momentos para responder, questionamentos, investigação colaborativa e curiosidade ${ }^{5}$.

\section{Conclusão}

A prática de Movimento Autêntico enfatiza um continuum de linguagem e movimento,

5 Essa ideia foi inspirada em parte pela recente onda de eventos do tipo "conferência sem papel" ('No paper conference', no original) (2014) e "Longas Mesas sobre arte ao vivo e feminismo" ('Long table on live art and feminism', no original) (2014), que incluem conversa e interação social como parte do processo de troca na pesquisa. Na conferência Dance and Somatic Practices (Coventry University, 2015), eu também fui co-organizadora num evento relacionado com Hetty Blades, Paula Kramer e Alys Longely chamado 'Diálogos Abertos, remixados, inacabados, começados: Um fórum para pesquisadores e artistas iniciantes e iniciados (Open Dialogues, remixed, unfinished, begun: A forum for early-to-mid-career researchers and artists', no original). 
exemplificada no desenvolvimento do "paradigma movente-testemunha" (Goldhahn, 2007, p.14). Inicialmente, o movente está traçando impulso interior e expressão de movimento no espaço, compartilhando isso com a testemunha através da escrita e da fala, com a testemunha retornando essa reflexão através da linguagem. Adler (2002, 2014) descreve seus experimentos com esses procedimentos através de "texto encarnado", que explora a escrita poética decorrente da prática de Movimento Autêntico, mas também através do "círculo de dança" onde gestos da sessão de movimento são recriados e repetidos por moventes e testemunhas. Portanto, movimento e linguagem são explorados no Movimento Autêntico como formas alternativas e complementares de movimento reflexivo e de testemunho. Em vez de separar movimento e linguagem, tentei entrelaçá-los em Speak e não postular o corpo como mais "autêntico" do que a linguagem, mas sim procurar encontrar as conexões e interrupções entre corpo e linguagem através do soma.

Minha investigação em linguagem na prática de Movimento Autêntico tornou-se parte de um questionamento sobre as atitudes em relação à linguagem e ao corpo que encontro em diferentes contextos. Por um lado, encontrei a suspeita da linguagem substituindo a prática encarnada e os insights, e, por outro lado, um acolhimento da linguagem como um processo pelo qual a experiência encarnada pode ser refletida e explorada. Durante minha performance como projeto de pesquisa aprendi como a linguagem torna-se parte da experiência em movimento, como um meio de reflexão e articulação. A prática também revelou dificuldades para mim, ao trazer para a performance partituras de movimento pré-ensaiadas e escritas desenvolvidas a partir da prática de
Movimento Autêntico. Especificamente, senti que havia uma lacuna entre o texto pré-escrito, o re-proferir deste através da fala, e a nova informação que eu estava recebendo de meu corpo-mente no momento da performance, já que eu estava me experimentando num contexto completamente novo. No futuro, pretendo explorar conversas e diálogos como formas de intercâmbio de linguagem-movimento nas configurações de performance e de pesquisa, repensanso como os materiais da prática de Movimento Autêntico subjazem novas interações e podem também desenvolver ou alterar através do processo de 'oferta'.

Este artigo está situado no campo em rápida expansão da prática como pesquisa, com implicações para os modos como o trabalho é feito e articulado. Ele aborda as formas com que a pesquisa baseada na prática ocorre em atos de corpo-mente, como esse processo pode ser articulado e como o praticante-pesquisador pode se comunicar através das configurações dentro das quais opera. Desta forma, o papel da linguagem em relação à prática, especificamente o movimento, torna-se pertinente para explorar e questionar. $\mathrm{O}$ artigo responde a perguntas sobre o que a prática de Movimento Autêntico pode oferecer, em termos de análise de como movimento e linguagem se relacionam entre si, e que métodos podem haver ao cruzá-los quando da escrita sobre a experiência da performance. Proponho o emprego de práticas de testemunho, experimentos com texto incorporado e também o potencial para explorar conversas e diálogos em partilhas de pesquisas baseadas na prática.

Este artigo é um breve resumo de um processo mais amplo e pode somente tocar em questões de movimento e linguagem na 
performance e da pesquisa baseada na prática. Pesquisas e práticas posteriores poderiam investigar relações entre o Movimento Autêntico e conceitos psicanalíticos de linguagem, tais como a teoria lacaniana da criança ingressando na "ordem simbólica" estruturada no momento da aquisição da linguagem. Tal pesquisa desenvolveria a compreensão da percepção e de experiências psicofísicas de 'ruptura' ou divisão entre corpo e linguagem. A prática de Movimento Autêntico como uma disciplina atinge campos de terapia com seus insights reflexivos, e da performance como uma forma de expressão criativa, mas também é considerada uma prática espiritual. A partir desta última vertente, uma investigação sobre a relação entre corpo, linguagem e práticas de conscientização ou meditação também pode ser útil. Isso poderia iluminar alguns desafios da articulação entre o pensamento e a linguagem nessas práticas. Por exemplo, o líder espiritual Eckhart Tolle (2015) propõe que existem problemas com "pensamento, ou mais precisamente a identificação com o pensamento" e "pensamento sem consciência", enquanto ele também afirma que "as palavras são somente ponteiros ... o que está sendo comunicado encontra-se além das palavras, mas podemos usá-las para ir pelo menos no sentido de que se entendem e que são úteis". Está para além do âmbito desse artigo considerar plenamente o impacto do conhecimento nessas muitas vertentes do terapêutico, do criativo e do espiritual, numa compreensão da relação entre movimento e linguagem na prática de Movimento Autêntico. No entanto, tentei argumentar aqui sobre a interação complexa, porém entrelaçada, de cada um no Movimento Autêntico e as possibilidades que isso oferece para a performance e para a pesquisa baseada na prática.
Por fim, esse artigo se desenrolou ao longo do tempo através de um processo de escrever, mover-se, questionar, lutar, editar, consultar, conversar, revisar, trocar, revisar e re-escrever. Minha escrita é provisória pois continuo a experimentar e estou oferecendo minhas próprias palavras vividas num momento particular no tempo, que eu espero que encontre debate e mudança.

Referências

ADLER, Janet. Offering from the Conscious Body: The Discipline of Authentic Movement, Rochester: Inner Traditions, 2002.

BACON, Jane; MIDGELOW, Vida. Closer to the body: Reflections on Skript and extracts from collected writings. Choreographic Practices, v. 5, n. 1, p. 73-94, 2014a.

Creative Articulations Process (CAP), Choreographic Practices, v. 5, n. 1, p. 7-31, 2014b.

BAINBRIDGE COHEN, Bonnie. Sensing Feeling and Action: The Experiential Anatomy of Body-Mind Centering, Northampton, MA: Contact Editions, 1993.

BANNERMAN, Henrietta. Choreographers reflexive writing: a very special practice. Forum for Modern Language Studies, v. 46, n. 4, p. 474-87, 2010. Disponível em http://fmls. oxfordjournals.org/content/46/4/474.full?keytype=ref\&ijkey=r2TzcHCapvCZVXI. Acesso em 2 fev. 2015. 
DAVIS, Joan. Maya Lila: Bringing Authentic Movement into Performance - The Process, Norfolk: Elmdon Books, 2007..

DERRIDA, Jacques. 'Différance', in Margins of Philosophy. Brighton: Harvester Press, pp. 1-28, 1982.

GOLDHAHN, Eila. Shared habitats: The mover-witness paradigm. Tese de Doutorado. Devon: University of Plymouth and Dartington College of Arts, 2007.

GRAU, Andrée. Dancing bodies, spaces/places and the senses: A cross-cultural investigation. Journal of Dance \& Somatic Practices, v. 3, n. 1-2, p. 5-24, 2012.

GROZ, Elizabeth. The body of signification. In CUONSELL, C. (ed.), Performance Analysis: An Introductory Coursebook, London: Routledge., p. 140-145, 2005.

Institute of Philosophy - Academy of Sciences of the Czech Republic. No paper conference, 2014. Dispnonível em http://web.flu.cas.cz/ filosofievexperimentu/nopaper/. Acesso em 9 fev 2015.

KRISTEVA, Julia. Revolution in Poetic Language. New York: Columbia University Press, 1984.

LEPECKI, André; BANES, Sally. Introduction: The performance of the senses. In LEPECKI, A.; BANES,S. (eds), The Senses in Performance. London and New York: Routledge, 2007, p. $1-7$.
Live Art Development Agency - Long table on live art and feminism, 2014. Disponível em http://www.thisisliveart.co.uk/blog/long-table-on-live-art-and-feminism-with-lois-weaver. Acesso em 9 fev. 2015.

LONGELY, Alys. Moving words: Five instances of dance writing. Tese de Doutorado. Melbourne: Victoria University, 2010.

MURRAY, Simon; KEEFE, John. Physical Theatres: A Critical Introduction, London: Routledge, 2007.

NELSON, Robin (2013), Practice as Research in the Arts: Principles, Protocols, Pedagogies and Resistances. Basingstoke: Palgrave Macmillan, 2013.

PHELAN, Peggy. Dance and the history of Hysteria. In FOSTER, S. L. (ed.). Corporealities: Dancing Knowledge, Culture and Power, London: Routledge, 1996, p. 92-108.

SARCO-THOMAS, Malaika. Touch + talk: Ecologies of questioning in contact and improvisation. Journal of Dance \& Somatic Practices, v. 6, n.2, p. 189-204, 2014.

STROMSTED, Tina; HAZE, Neala. The road in: Elements of the study and practice of authentic movement. In PALLARO, P. (ed.). Authentic Movement: Moving the Body, Moving the Self, Being Moved. London: Jessica Kinsley, 2007, pp. 56-68. 
TOLLE, Eckhart. 'Awakening to your life's purpose' (by Kathy Juline), 2015. Disponível em https://www.eckharttolletv.com/article/Awakening-Your-Spiritual-Lifes-Purpose/. Acesso em 22 junho 2015.

WOLFF, Janet. Dance criticism: Feminism, theory and choreography. In GAY, J. de; GOODMAN, L. (eds). The Routledge Reader in Gender and Performance, London: Routledge, 1998.

Recebido: 21/10/2016 Aprovado: 25/10/2016 